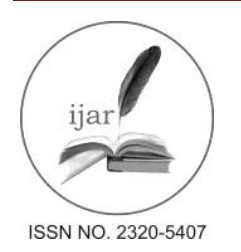

Journal homepage:http://www.journalijar.com

Journal DOI:10.21474/IJAR01

RESEARCH ARTICLE

\title{
ASYMPTOMATIC CAROTID ARTERY PREVALENCE IN CRITICAL LIMB ISCHEMIA IN SOUTH INDIAN POPULATION.
}

\author{
Marunraj Gnanasekaran ${ }^{1}$, Prabakar Dilliraj ${ }^{2}$ and Subrammaniyan $\mathbf{S} \mathbf{R}^{\mathbf{3}}$. \\ 1. Associate professor of vascular surgery, saveetha medical college, Thandalam. \\ 2. Consultant Vascular surgeon, Yasodha Hospitals, Hyderabad. \\ 3. Professor of vascular surgery, saveetha medical college, Thandalam.
}

\section{Manuscript Info Abstract}

\section{Manuscript History:}

Received: 12 May 2016

Final Accepted: 22 June 2016

Published Online: July 2016

Key words:

Asymptomatic carotid artery stenosis(ACAS), Carotid duplex ultrasonography(CDUS), Critical limb ischemia(CLI),

Cerebrovascular disease(CVD),

Atherosclerotic Occlusion (ASO).

*Corresponding Author

Marunraj Gnanasekaran.

\begin{abstract}
Aim: -To study the prevalence of ASYMPTOMATIC CAROTID ARTERY DISEASE and to identify predictive factors of carotid artery disease, in patients with critical limb ischemia in south Indian patients

Materials and methods: -Total of 250 patients with critical limb ischemia admitted in department of vascular surgery, madras medical college, Chennai, underwent carotid duplex scanning by department of radiology, madras medical college, Chennai and a questionnaire was used to collect data concerning known risk factors.

Results: - The mean age of the patients was $50 \pm 20$ years; there were 242 (96.8\%) men and $8(3.2 \%)$ women; $72 \%$ of the patients had a history of smoking, $10.4 \%$ had coronary artery disease, 5.6\% had hypertension, $5.6 \%$ had dyslipidemia and $17.2 \%$ had diabetes mellitus. Eighteen (7\%) patients had carotid artery disease detected by carotid artery duplex scanning of which insignificant Carotid artery disease found in 10 patients, significant carotid artery stenosis in 5 patients and complete occlusion of ICA in 3 patients.

Conclusion: -All patients with peripheral vascular disease with large vessel occlusion due to atherosclerosis have to be screened for carotid artery disease.
\end{abstract}

Copy.Right. IJAR 2016... All rights reserved.

\section{Introduction:-}

Carotid artery disease is associated with a risk of stroke. Approximately $88 \%$ of strokes are ischemic and about $20 \%$ of these originate from large artery stenosis. To prevent ischemic stroke, carotid endarterectomy has been recommended for asymptomatic patients with severe carotid stenosis based on evidence of multicentre prospective randomized trials. Carotid duplex ultrasonography (CDUS) is an accuracy-proven non-invasive diagnostic examination to detect asymptomatic carotid artery stenosis (ACAS). However, for the general population, CDUS has a limited role in screening of carotid disease because of a low overall prevalence of clinically relevant disease. Because coronary artery disease, cerebrovascular disease (CVD) and peripheral arterial disease (PAD) originate from atherosclerosis, these three diseases occasionally exist together. Therefore, screening CDUS may be useful for those populations. Several previous studies reported that the prevalence of ACAS was relatively high in patients with critical limb ischemia. In India, the prevalence of asymptomatic carotid artery disease in patients with critical limb ischemia has not yet.

\section{Method and materials:-}

Carotid duplex scan was done for all 250 patients by the Radiology department and Carotid lesions weredocumented using ModifiedWashington duplex criteria. 
Modified Washington duplex criteria

\begin{tabular}{|l|l|l|l|}
\hline Stenosis & PSV & EDV & Spectrum \\
\hline Normal & $<125 \mathrm{~cm} / \mathrm{s}$ & & Normal with no plaque \\
\hline $1-15 \%(B)$ & $<125 \mathrm{~cm} / \mathrm{s}$ & & Normal with plaque \\
\hline $16-49 \%(\mathrm{C})$ & $<125 \mathrm{~cm} / \mathrm{s}$ & & Broadening \\
\hline $50-79 \%(\mathrm{D})$ & $>125 \mathrm{~cm} / \mathrm{s}$ & $<140 \mathrm{~cm} / \mathrm{s}$ & Broadening \\
\hline $80-99 \%(\mathrm{D}+)$ & $>125 \mathrm{~cm} / \mathrm{s}$ & $>140 \mathrm{~cm} / \mathrm{s}$ & Broadening \\
\hline Occluded (E) & No flow & No flow & No flow \\
\hline
\end{tabular}

PSV, peak systolic velocity; EDV, end diastolic velocity; $\mathrm{cm} / \mathrm{s}$, centimetres per second; CCA, common carotid artery; ICA, internal carotid artery; ECA, external carotid artery.

EDV: $80 \mathrm{~cm} / \mathrm{s} \sim 60 \% ; 100 \mathrm{~cm} / \mathrm{s} \sim 70 \%$

ICA:CCA PSV ratio: $3.2 \sim 60 \% ; 4.0 \sim 70 \%$

\section{Observation and results:-}

The carotid disease was present in 18 of 250 patients studied, which represents valid percentage of 7.2. The age pattern of carotid disease was shown in bar chart

\section{Bar chart. 1 - age \& carotid disease}

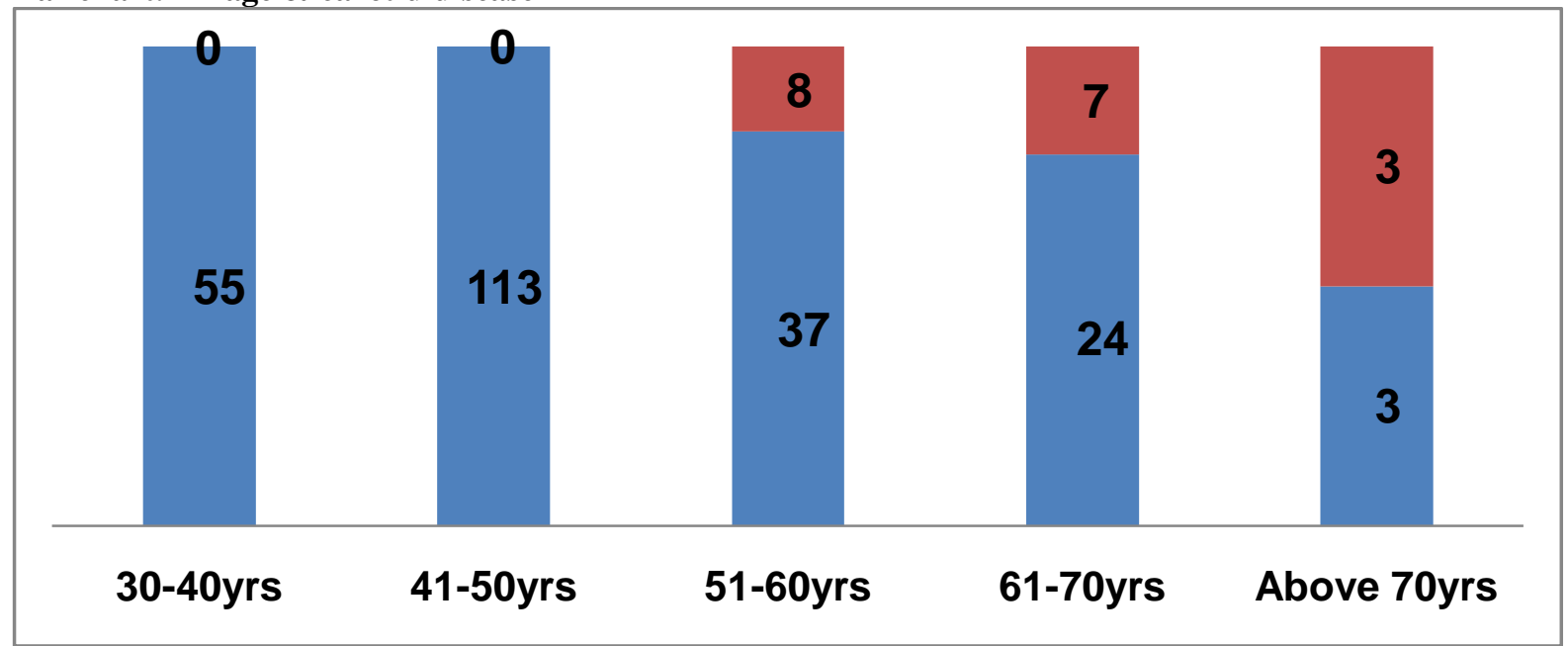

\section{ABSENT PRESENT}

The predictive factors of carotid disease and its stastical significance were shown in the following tables from

Table 1 to 5.

Table 1:- diabetic mellitus \& carotid disease.

\begin{tabular}{|c|c|c|c|c|c|}
\hline & & & & & \\
\hline & & & Absent & Present & Total \\
\hline DM & No & Count & 200 & 7 & 207 \\
\hline & & \% within DM & $96.6 \%$ & $3.4 \%$ & $100.0 \%$ \\
\hline & Yes & Count & 32 & 11 & 43 \\
\hline & & \% within DM & $74.4 \%$ & $25.6 \%$ & $100.0 \%$ \\
\hline & Total & Count & 232 & 18 & 250 \\
\hline & & \% within DM & $92.8 \%$ & $7.2 \%$ & $100.0 \%$ \\
\hline
\end{tabular}


Table 2:-hypertension \& carotid disease.

\begin{tabular}{|c|c|c|c|c|c|}
\hline & & & \multicolumn{2}{|c|}{ Carotid Disease } & \\
\hline & & & Absent & Present & Total \\
\hline \multirow[t]{4}{*}{ HT } & \multirow[t]{2}{*}{ No } & Count & 220 & 13 & 233 \\
\hline & & $\%$ within $\mathrm{HT}$ & $94.4 \%$ & $5.6 \%$ & $100.0 \%$ \\
\hline & \multirow[t]{2}{*}{ Yes } & Count & 12 & 5 & 17 \\
\hline & & $\%$ within $\mathrm{HT}$ & $70.6 \%$ & $29.4 \%$ & $100.0 \%$ \\
\hline & \multirow[t]{2}{*}{ Total } & Count & 232 & 18 & 250 \\
\hline & & $\%$ within HT & $92.8 \%$ & $7.2 \%$ & $100.0 \%$ \\
\hline
\end{tabular}

Table 3:-cad \& carotid disease.

\begin{tabular}{|c|c|c|c|c|c|}
\hline & & & \multicolumn{2}{|c|}{ Carotid Disease } & \\
\hline & & & Absent & Present & Total \\
\hline \multirow[t]{3}{*}{ CAD } & \multirow[t]{2}{*}{ No } & Count & 221 & 3 & 224 \\
\hline & & $\%$ within CAD & $98.7 \%$ & $1.3 \%$ & $100.0 \%$ \\
\hline & Yes & $\%$ within CAD & $42.3 \%$ & $57.7 \%$ & $100.0 \%$ \\
\hline & Total & Count & 232 & 18 & 250 \\
\hline
\end{tabular}

Table 4:-dyslipidemia \& carotid disease

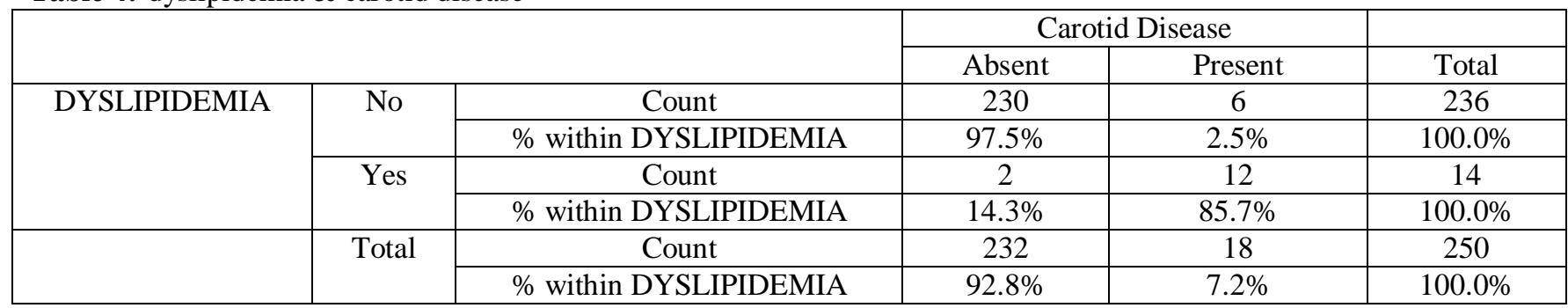

Table 5:-smoking \& carotid disease

\begin{tabular}{|c|c|c|c|c|c|}
\hline & & & \multicolumn{2}{|c|}{ Carotid Disease } & \\
\hline & & & Absent & Present & Total \\
\hline \multirow[t]{6}{*}{ SMOKER } & \multirow[t]{2}{*}{ No } & Count & 62 & 8 & 70 \\
\hline & & $\%$ within SMOKER & $80.0 \%$ & $20.0 \%$ & $100.0 \%$ \\
\hline & \multirow[t]{2}{*}{ Yes } & Count & 170 & 10 & 180 \\
\hline & & $\%$ within SMOKER & $95.2 \%$ & $4.8 \%$ & $100.0 \%$ \\
\hline & \multirow[t]{2}{*}{ Total } & Count & 232 & 18 & 250 \\
\hline & & $\%$ within SMOKER & $92.8 \%$ & $7.2 \%$ & $100.0 \%$ \\
\hline
\end{tabular}


The etiopathological pattern of carotid disease was shown with stastical data in pie chart and table 6 .

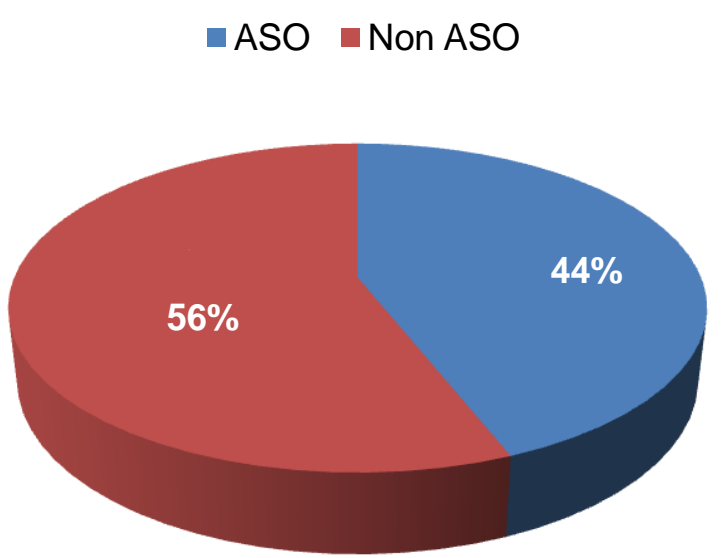

Table 6:-etiopathology \& carotid disease.

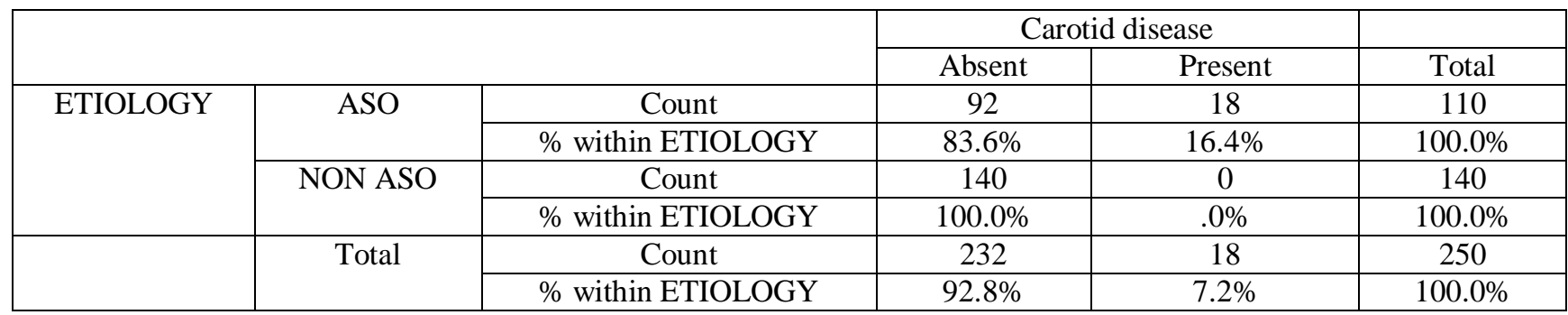

\section{Discussion:-}

Two hundred and fifty consecutive patients were studied over 1 year. The mean age of the patients was $50 \pm 20$ years; there were $242(96.8 \%)$ men and $8(3.2 \%)$ women; $72 \%$ of the patients had a history of smoking, $10.4 \%$ had coronary artery disease, $5.6 \%$ had hypertension, $5.6 \%$ had dyslipidemia and $17.2 \%$ had diabetes mellitus. Eighteen (7\%) patients had carotid artery disease detected by carotid artery duplex scanning of which insignificant Carotid artery disease found in 10 patients, significant carotid artery stenosis in 5 patients and complete occlusion of ICA in 3 patients.

\section{Risk Estimate}

\begin{tabular}{|l|l|l|l|}
\hline & & \multicolumn{2}{|l|}{$95 \%$ confidence interval } \\
\hline & Value & Lower & Upper \\
\hline Odds Ratio for DM & 9.821 & 3.547 & 27.195 \\
\hline Odds Ratio for HT & 7.051 & 2.159 & 23.035 \\
\hline Odds Ratio for CAD & 100.4 & 25.28 & 399.12 \\
\hline $\begin{array}{l}\text { Odds Ratio for } \\
\text { Dyslipidemia }\end{array}$ & 230 & 41.92 & 1261.896 \\
\hline Odds Ratio for Smoker & 0.200 & & 0.545 \\
\hline Odds Ratio for Etiology & 0.836 & 0.073 & 0.908 \\
\hline
\end{tabular}

The $\mathrm{P}$ value was stastically significant $(<0.05)$ for all parameters

In this study patients with critical limb ischemia due to non-atherosclerotic disease were $56 \%$ and due to atherosclerotic disease were 44\%.In this study there is no prevalence of carotid disease in patients with critical limb ischemia due to non-atherosclerotic disease. The prevalence of asymptomatic carotid disease in critical limb ischemia patients is more common in elderly age group and in patients with DM,CAD and dyslipidemia (p < 0.05 ) which is statistically significant. The asymptomatic carotid disease is more prevalent in patients with large vessel 
occlusion(Aorta,Iliac level occlusion). The asymptomatic carotid disease is present only in patients with atherosclerotic occlusive disease (16.4\%) similar to other studies reported. On multivariate analysis dyslipidemia, coronary artery disease and DM seemed to have independent influence $(\mathrm{p}<0.05)$ which is statistically significant.

\section{Conclusion:-}

The prevalence of asymptomatic carotid artery disease in Indian subgroup patients with critical limb ischemia is $7 \%$. However this study demonstrates a relatively high prevalence of carotid artery disease in patients with peripheral arterial disease due to atherosclerotic occlusion of $16.4 \%(\mathrm{p}<0.05)$ which is statistically significant.All patients with peripheral vascular disease with large vessel occlusion due atherosclerosis have to be screened for carotid artery disease.

\section{Bibliography:-}

1. Warlow C. Endarterectomy for asymptomatic carotid stenosis? Lancet 1995; 345(8960):1254-55.

2. Amarenco P, Cohen A, Tzourio C, Bertrand B, Hommel M, Besson G, et al. Atherosclerotic disease of the aortic arch and the risk of ischemic stroke. N Engl J Med 1994; 331(22):1474-9.

3. Blakeley DD, Oddone EZ, Hasselblad V, Simel DL, Matchar DB. Noninvasive carotid artery testing. A metaanalytic review. Ann Intern Med 1995; 122(5):360-7.

4. Ballotta E, Da Giau G, Abbruzzese E, Saladini M, Renon L, Scannapieco G et al. Carotid endarterectomy without angiography: can clinical evaluation

5. and duplex ultrasonographic scanning alone replace traditional arteriography for carotid surgery workup? A prospective study. Surgery 1999; 126(1):20-7.

6. Colgan MP, Strode GR, Sommer JD, Gibbs JL, Sumner DS. Prevalence of asymptomatic carotid disease: results of duplex scanning in 348 unselected volunteers. J Vasc Surg 1988; 8(6):674-8.

7. Chambers BR, You RX, Donnan GA. Carotid endarterectomy for asymptomatic carotid stenosis. Cochrane Database Syst Rev 2000;(2):CD001923.

8. Minar E. Peripheral arterial occlusive disease. Vasa 2007; 36(3):155-64.

9. Ballotta E, Da Giau G, Renon L, Abbruzzese E, Saladini M, Moscardo P et al. Symptomatic and asymptomatic carotid artery lesions in peripheral vascular disease: a prospective study. Int J Surg Investig 1999; 1(4):357-63.

10. House AK, Bell R, House J, Mastaglia F, Kumar A, D'Antuono M. Asymptomatic carotid artery stenosis associated with peripheral vascular disease: a prospective study. Cardiovasc Surg 1999; 7(1):44-9.

11. Klop RB, Eikelboom BC, Taks AC. Screening of the internal carotid arteries in patients with peripheral vascular disease by colour-flow duplex scanning. Eur J Vasc Surg 1991; 5(1):41-5.

12. Ahn SS, Baker JD, Walden K, Moore WS. Which asymptomatic patients should undergo routine screening carotid duplex scan? Am J Surg 1991; 162(2):180-3.

13. Ascher E, DePippo P, Salles-Cunha S, Marchese J, Yorkovich W. Carotid screening with duplex ultrasound in elderly asymptomatic patients referred to a vascular surgeon: is it worthwhile? Ann Vasc Surg 1999; 13(2): 164-8.

14. Rancic Z, Radak D, Stojanovic D. Early detection of asymptomatic carotid disease in patients with obliterative arteriosclerosis of the lower extremities. Srp Arh Celok Lek 2002; 130(7-8):258-64.

15. Pilcher JM, Danaher J, Khaw KT. The prevalence of asymptomatic carotid artery disease in patients with peripheral vascular disease. Clin Radiol 2000; 55(1):56-61. 